Research Article

\title{
Field Study on the Law of Surface Subsidence in the High-Intensity Fully Mechanized Caving Mining Working Face with Shallow Thick Bedrock and Thin Epipedon in Hilly Areas
}

\author{
Yi Tan $\mathbb{D}^{1,},{ }^{1,2,3,4}$ Hao Cheng, ${ }^{1,2}$ Shuang Gong $\mathbb{D}^{1,2}$ Erhu Bai, ${ }^{1,2,3}$ Minchao Shao, ${ }^{5}$ \\ Bingyuan Hao, ${ }^{6}$ Xiaoshuang $\mathrm{Li}\left(\mathbb{D},{ }^{7}\right.$ and $\mathrm{Han} \mathrm{Xu}^{1,2}$ \\ ${ }^{1}$ School of Energy Science and Engineering, Henan Polytechnic University, Jiaozuo 454000, China \\ ${ }^{2}$ State Collaborative Innovation Center of Coal Work Safety and Clean-Efficiency Utilization, Henan Province, \\ Jiaozuo 454000, China \\ ${ }^{3}$ Xi'an University of Science and Technology, State Key Laboratory of Coal Resources in Western China, \\ Xi'an University of Science and Technology, Xi'an 710054, China \\ ${ }^{4}$ State Key Laboratory of Water Resource Protection and Utilization in Coal Mining, Beijing 100011, China \\ ${ }^{5}$ Shanxi Yamei Daning Energy Co.,Ltd, Shanxi Province, Jincheng 048000, China \\ ${ }^{6}$ College of Mining Engineering, Taiyuan University of Technology, Taiyuan 030000, China \\ ${ }^{7}$ School of Civil Engineering, Shaoxing University, Shaoxing 312000, China \\ Correspondence should be addressed to Shuang Gong; gongcumtb@126.com
}

Received 11 November 2021; Accepted 29 November 2021; Published 11 December 2021

Academic Editor: Zhengyang Song

Copyright $\odot 2021$ Yi Tan et al. This is an open access article distributed under the Creative Commons Attribution License, which permits unrestricted use, distribution, and reproduction in any medium, provided the original work is properly cited.

\begin{abstract}
Shallow and thick coal seams occur extensively in hilly areas in Shanxi Province and Shaanxi Province, China. The surface damage and landslides caused by shallow fully mechanized caving mining have a very serious impact on the environment. To provide a theoretical and reference foundation for mine environmental protection in hilly settings, a research on surface movement of the high-intensity fully mechanized caving mining working face with shallow thick bedrock and thin epipedon (HIFMCMWFSTBTE) is urgently needed. In this study, using the P2 working face of a mine as the research object, three surface subsidence observation lines were arranged in this working face to analyze the dynamic change characteristics of surface subsidence. Besides, the law of surface movement, mining sufficiency, fracture development and distribution characteristics, subsidence speed, and surface movement duration of HIFMCMWFSTBTE in hilly areas were comparatively studied. The research results reveal that the upper part of the slope slides towards the downhill direction under the action of tensile stress or push stress. As a result, the range of the horizontal movement towards the downhill direction of the slope and the range of surface movement both increase, and the movement angle and boundary angle both decrease compared with the plain. HIFMCMWFSTBTE is prone to serious sudden discontinuous damage. Fractures on the gully region surface develop along the contour, forming a crisscross fracture network, and the fractures are not easy to close after being generated. HIFMCMWFSTBTE in hilly areas can achieve full mining more easily than those of other geological conditions. According to the field measurement, critical full mining can be achieved in P2 working face when the ratio of mining width to mining depth is 1.07. The surface movement duration of HIFMCMWFSTBTE in hilly areas is relatively short. Considerable subsidence will occur in the active stage, and the surface subsidence is sudden and violent. The measured surface stabilization time of the P2 working face is only $20 \%$ of the calculated value in the Specification for Coal Pillar Reservation and Coal Mining under Buildings, Water Bodies, Railways, and Main Shafts (hereinafter referred to as the Specification), indicating that the specification's empirical formula is inapplicable to the calculation of surface stabilization time of the P2 working face.
\end{abstract}




\section{Introduction}

Before an underground coal seam is mined, the rock remains in a relatively balanced state under the action of in situ stress field. When the coal seam is partially mined, a gob area is formed inside the rock, and the stress equilibrium state of the surrounding rock gets destroyed, causing stress redistribution [1-3]. Thereafter, the rock undergoes movement, deformation and failure until a new balance is reached. Finally, surface subsidence occurs, which causes damage to surface buildings and structures [4, 5]. Many researchers have carried out a large number of laboratory experiments on the mechanical properties and deformation characteristics of coal and rock. For example, Song et al. [6, 7] investigate the evolution of deformation and damage related parameters as well as the hysteresis behavior on Tibet marble. The test results show that an increase of FT cycles and fatigue load level both accelerate the damage rate of marble. Based on two different cyclic loading strategies, it is concluded that the maximum load level has a more pronounced effect on energy dissipation than the minimum load level [8]. Scholars [9-14] found that the laws of surface subsidence caused by different mining geological conditions differ significantly. Useful conclusions were drawn through a series of studies on the mining-induced surface subsidence from the aspects of bedrock thickness, buried depth, mining sufficiency, and so on. Meanwhile, it is also found in relevant researches [15-17] that due to the influence of surface topography, the surface topography damage, subsidence law, and construction protection of hilly areas are quite different from those of plain areas. Gao [18] studied the surface subsidence law under conditions of thick bedrock and large mining depth and found that the boundary angle value is small and the surface subsidence influence range is large due to the influence of multiple groups of thick and hard sandstone layers. Peng and Song et al. [19, 20] analyzed and summarized the surface movement and deformation characteristics of loess gully landform and the key technologies of ecological restoration. Therefore, the study on the law of surface subsidence in HIFMCMWFSTBTE in hilly areas is of great significance for improving the basic theory of mining subsidence and guiding on-site production [21-27].

Shallow and thick coal seams occur extensively in hilly areas in Shanxi Province and Shaanxi Province, China. In view of this fact, with the fully mechanized caving mining P2 working face with shallow thick bedrock and thin epipedon in a mine taken as the engineering research object, the temporal and spatial evolution laws of surface movement in HIFMCMWFSTBTE in hilly areas under the same mining and geological conditions were summarized by combining the methods of field measurement and theoretical analysis. Important research results were obtained.

\section{Geological Mining Conditions and Layout of Observation Station}

2.1. Geological Mining Conditions. The designed production capacity of the mine is $4.0 \mathrm{Mt} / \mathrm{a}$, and its terrain is mainly low mountains and hills, of which the surface topography of P2 working face belongs to low mountains. The working face is covered by thin epipedon and partially exposed bedrock (Figure 1). In P2 working face, no. 3 coal seam, whose average thickness, dip angle, and buried depth are $4.8 \mathrm{~m}, 5.0^{\circ}$, and about $200 \mathrm{~m}$, respectively, is mined. The working face is $220 \mathrm{~m}$ wide, has a mining length of $1138 \mathrm{~m}$, and advances at the speed of $4 \mathrm{~m} / \mathrm{d}$. The method of fully mechanized caving towards long wall on strike is adopted for coal mining, and the method of total caving is used for roof management.

2.2. Layout of Observation Stations. Considering the distribution of thin epipedon and bedrock-exposing surface in P2 working face, one observation line on strike (line A) and two observation lines on inclination (lines $\mathrm{B}$ and $\mathrm{C}$ ) are arranged in P2 working face for obtaining the law of surface movement of HIFMCMWFSTBTE in hilly areas. Since the arrangement of observation stations and the first observation, a total of 12 observations have been conducted within about 16 months.

Observation Line A on Strike. With an epipedon thickness of $8 \mathrm{~m}$, Line A is $208 \mathrm{~m}$ in average buried depth and $830 \mathrm{~m}$ long. There are 37 observation points, among which points A1-A6, A17-A19, and A28-A32 are in the vicinity of bedrock-exposing surface, while the rest of the points are near loess-covering surface.

Observation Line B on Inclination. Line B is set $940 \mathrm{~m}$ away from the open-off cut and arranged along no. 2 gully. With an epipedon thickness of $0 \mathrm{~m}$, line B is $200 \mathrm{~m}$ in average buried depth and $660 \mathrm{~m}$ long. There are 30 measuring points, all of which belong to bedrock-exposing surface measuring points. Line B is entirely located in a basin.

Observation Line C on Inclination. Line C is laid $530 \mathrm{~m}$ away from the open-off cut. With an epipedon thickness of $6 \mathrm{~m}$, line $\mathrm{C}$ is $206 \mathrm{~m}$ in average buried depth and $680 \mathrm{~m}$ long. There are 36 measuring points, among which points C7-C17 are near bedrock-exposing, while the rest of the points are near loess-covering surface. Line $\mathrm{C}$ is entirely located in a basin. The layout of observation points in P2 working face is exhibited in Figure 2.

\section{Surface Subsidence Observation and Data Analysis}

3.1. Dynamic Distribution Characteristics of Subsidence Curve of Line A on Strike (Loess-Covering Surface). The observation line A on strike is arranged on the side of the stopping line of the working face. The analysis of the strike dynamic subsidence curve in Figure 3 demonstrates that, first, the ground observation starts from A1 towards A41 gradually (in Figure 3, the horizontal axis distance is the distance from each observation point to point A41) and ends after 8-13 observations are completed. After subsidence starts at each monitoring point on line A, the subsidence value gradually increases with the advancement of the working face. Afterwards, as the working face moves away from each point, the subsidence value gradually reaches the maximum under the geological mining conditions. Then, this value no longer grows. The point that reaches the maximum subsidence 


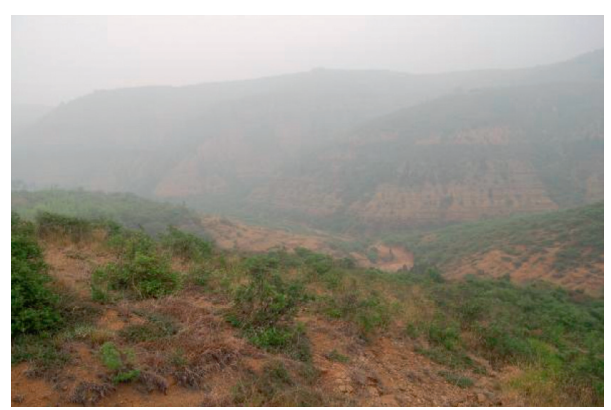

(a)

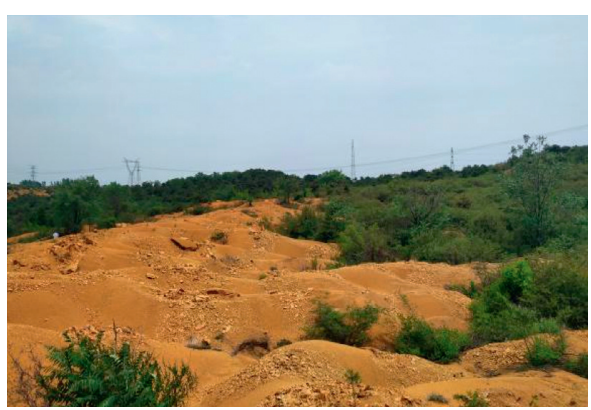

(b)

FIGURE 1: Surface conditions of P2 working face. (a) Loess-covering surface; (b) bedrock-covering surface.

value moves forward from A1 to A41 with the advancement of the working face. According to the results of the last four observations, the minimum and maximum subsidence values of points A18-A21 are $3335 \mathrm{~mm}$ and $3362 \mathrm{~mm}$, respectively. Besides, the subsidence value is $27 \mathrm{~mm}$ within six months. The results indicate that the surface subsidence tends to stabilize, and the flat bottom of the moving basin appears from A1 to A21. As the working face advances, the flat bottom of the moving basin stretches forward, and the subsidence value no longer rises. Point A32 is located in the ravine whose surface is uplifted.

\subsection{Dynamic Distribution Characteristics of Subsidence Curve} of Line B on Inclination (Bedrock-Exposing Surface). Line B, a curved observation line, is arranged along the ravine (Figure 4). Point B17 is the first to be affected by mining and to experience surface subsidence (during the 7 th observation) because it is the closest to the open-off cut. The maximum subsidence (the maximum subsidence value $2115 \mathrm{~mm}$ and the average subsidence speed $45 \mathrm{~mm} / \mathrm{d}$ ) is observed at point B15 on line B during the 8th and 9th observations, which last $47 \mathrm{~d}$. The results of the last four observations which last $153 \mathrm{~d}$ suggest that the maximum subsidence difference is $12 \mathrm{~mm}$, and the surface subsidence basically tends to stabilize, with the final maximum subsidence value being $3167 \mathrm{~mm}$.

\subsection{Dynamic Distribution Characteristics of Subsidence Curve} of Line $C$ on Inclination. The maximum subsidence (the maximum subsidence value $2363 \mathrm{~mm}$ and the average subsidence speed $118.2 \mathrm{~mm} / \mathrm{d}$ ) is observed at point C16 on line $\mathrm{C}$ during the fifth and sixth observations, which last $20 \mathrm{~d}$ (Figure 5). During the eighth and ninth observations which last $47 \mathrm{~d}$, the maximum subsidence value is consistent, and the surface subsidence basically tends to stabilize, with the final maximum subsidence value being $3419 \mathrm{~mm}$.

The dynamic distribution characteristics of tilt curve are shown in Figures 6-8. It can be seen from the curve that the surface inclination value changes from small to large with the advancement of the working face. During the 21st observation, the maximum value of inclination is $-41.7 \mathrm{~mm} / \mathrm{m}$ (point A29). From the 19th observation to the 21st observation, it can be seen that the moving deformation curve shows the antisymmetric characteristics of the inclined curve from the overall trend. The final distribution is different from that of flat land, which is mainly related to topographic factors. The maximum dynamic tilt deformation value in the strike direction is $-41.7 \mathrm{~mm} / \mathrm{m}$.

From the 13th observation to the 19th observation, the inclination change of inclination B observation line was small, and the regularity of observation results was not strong. Several observations after the 21st observation showed that the inclination reached the maximum value, and the maximum dynamic inclination deformation value of inclination direction was $55.6 \mathrm{~mm} / \mathrm{m}$ obtained from the 17th observation.

The tilt of observation line $\mathrm{C}$ changed little from the 13th observation to the 17th observation, and the regularity of observation results was not strong. Several observation results after the 21st observation showed that the surface movement deformation tended to be stable and reached the maximum tilt value. The maximum dynamic tilt deformation value in the trend direction was $48.6 \mathrm{~mm} / \mathrm{m}$ obtained from the 25th observation.

The dynamic distribution characteristics of curvature curve are shown in Figure 9. With the advancement of the working face, the surface curvature value gradually increases, and the negative curvature has double peak and multipeak phenomena. The distribution law of each observation is basically the same and only increases in value, but the positive and negative changes of the curvature value in the center of the basin have a large jump. It can be seen from the later observation curves that the curve shape is consistent and the value is basically stable. The maximum dynamic positive curvature deformation value in the strike direction is $+1.23 \mathrm{~mm} / \mathrm{m}^{2}$ and the maximum dynamic negative curvature deformation is $-2.70 \mathrm{~mm} / \mathrm{m}^{2}$.

Figures 10 and 11 show two trends of observation line curvature curves, B and C. The graphic depicts the change rule of different times. The maximum value and scope of the surface curvature steadily grow as the working face advances. The greatest curvature point remains almost constant. The prior observation curve's regularity is weak. The last few observations show obvious regularity, and the curve conforms to the general distribution law of curvature on flat land.

The maximum dynamic positive curvature deformation value of inclination $B$ observation line is $+1.34 \mathrm{~mm} / \mathrm{m}^{2}$, and the maximum dynamic negative curvature deformation value is $-1.13 \mathrm{~mm} / \mathrm{m}^{2}$. 


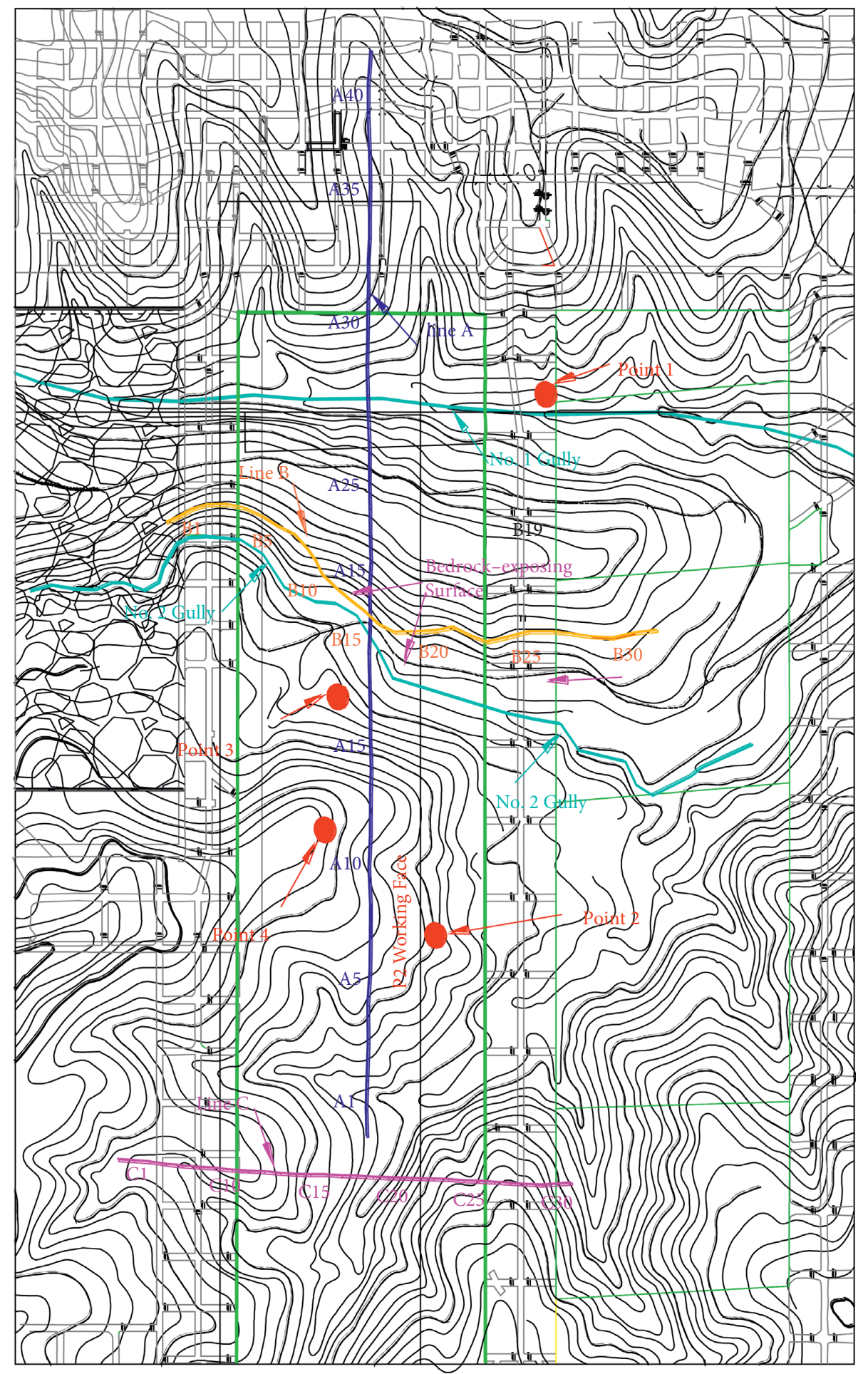

FIGURE 2: Layout of measuring points and comparison between the time of mining subsidence observation and the mining progress. 


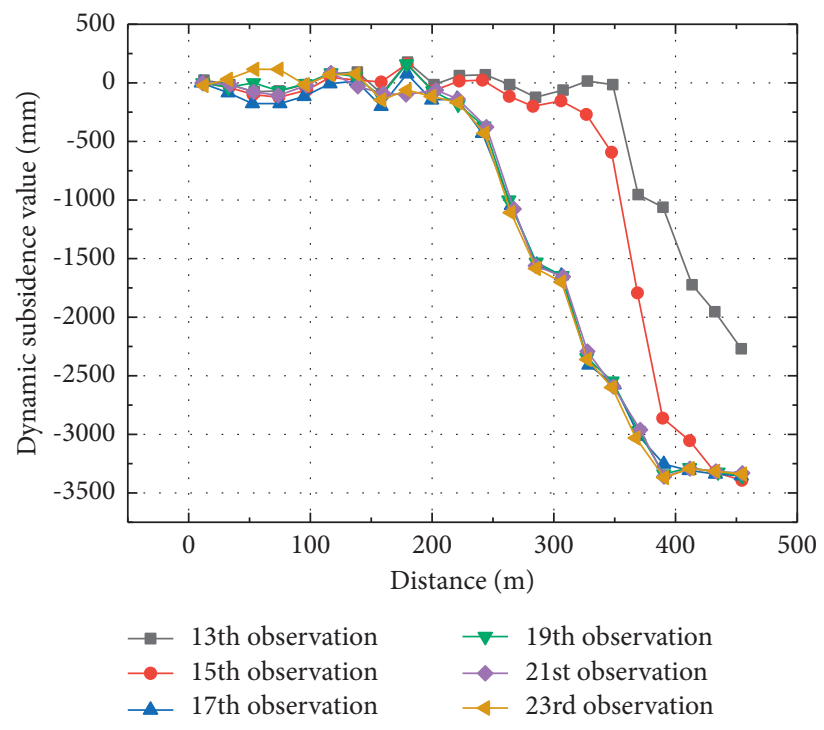

Figure 3: Dynamic change curve of subsidence of line A on strike.

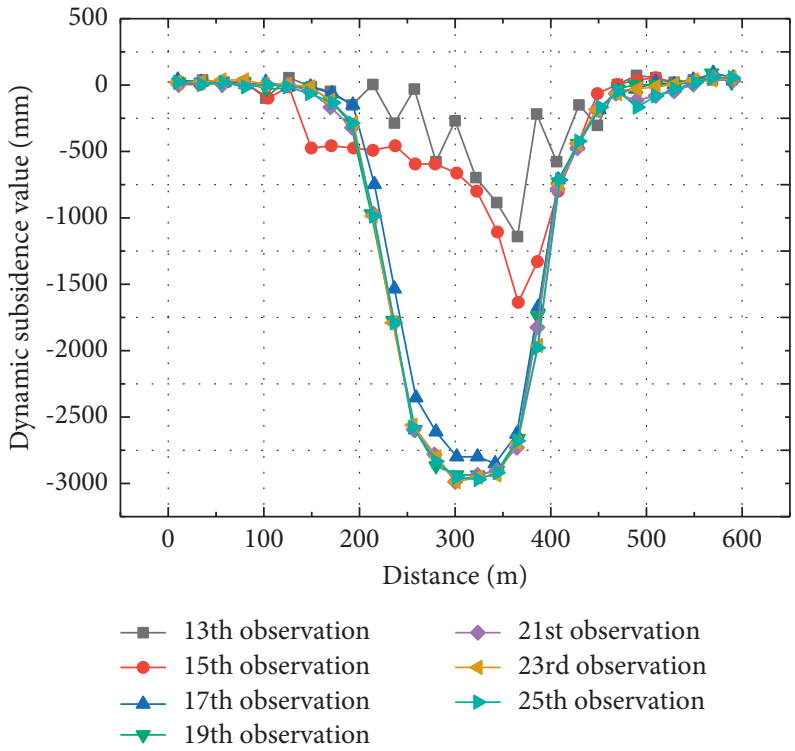

Figure 4: Dynamic change curve of subsidence of line B on inclination.

The maximum dynamic positive curvature deformation value of inclination $\mathrm{C}$ observation line is $+1.15 \mathrm{~mm} / \mathrm{m}^{2}$, and the maximum dynamic negative curvature deformation value is $-1.30 \mathrm{~mm} / \mathrm{m}^{2}$.

\section{Surface Subsidence Topography and Characteristics}

4.1. Particularity of Law of Surface Movement in Hilly Areas. The mining-induced surface movement in hilly areas can be classified into two forms. One is continuous movement deformation, that is, mining-induced slides in hilly areas, and the other is discontinuous movement deformation, that is, mining-induced fractures, landslides, and collapses in hilly areas. Compared with mining in the plain, mining in hilly areas exhibits different regularities which are displayed in the following aspects.

4.1.1. Characteristics of Surface Movement and Deformation in Hilly Areas. Because of the slopes in hilly areas, the rock slide or landslide caused by underground mining will result in an increase in horizontal movement towards the downhill direction. Meanwhile, due to the occurrence of mininginduced slide, the upper part of the slope slides downhill under the action of tensile stress or push stress, thus promoting horizontal movement and subsidence towards the downhill direction. Affected by mountain sliding, deformation and extrusion occur, leading to the surface uplift at the ravine. Damaged fractures caused by tensile stress in the upper part of the slope are depicted in Figure 12, from which 


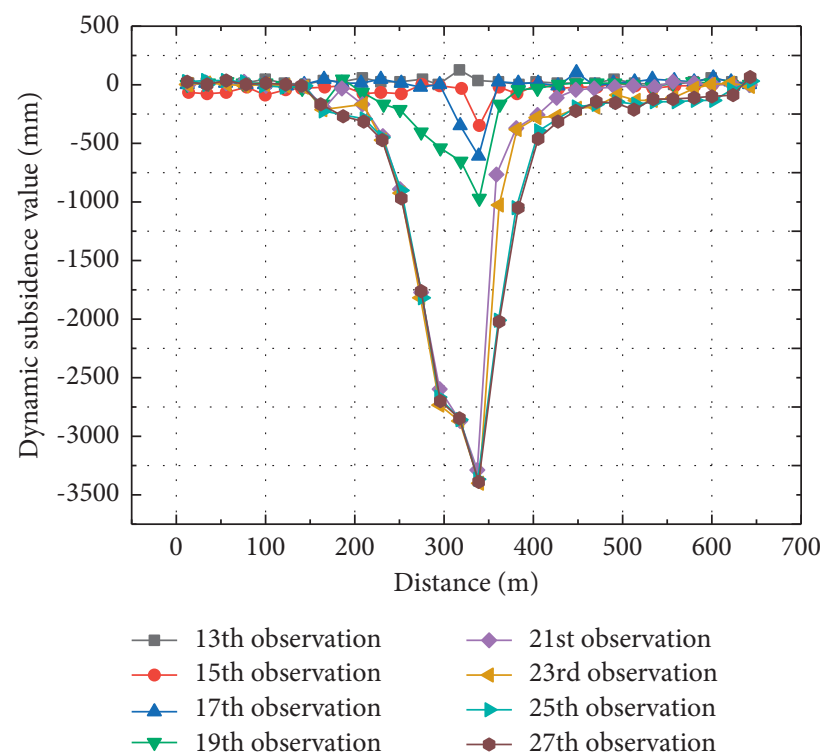

FIgURE 5: Dynamic change curve of subsidence of line $\mathrm{C}$ on inclination.

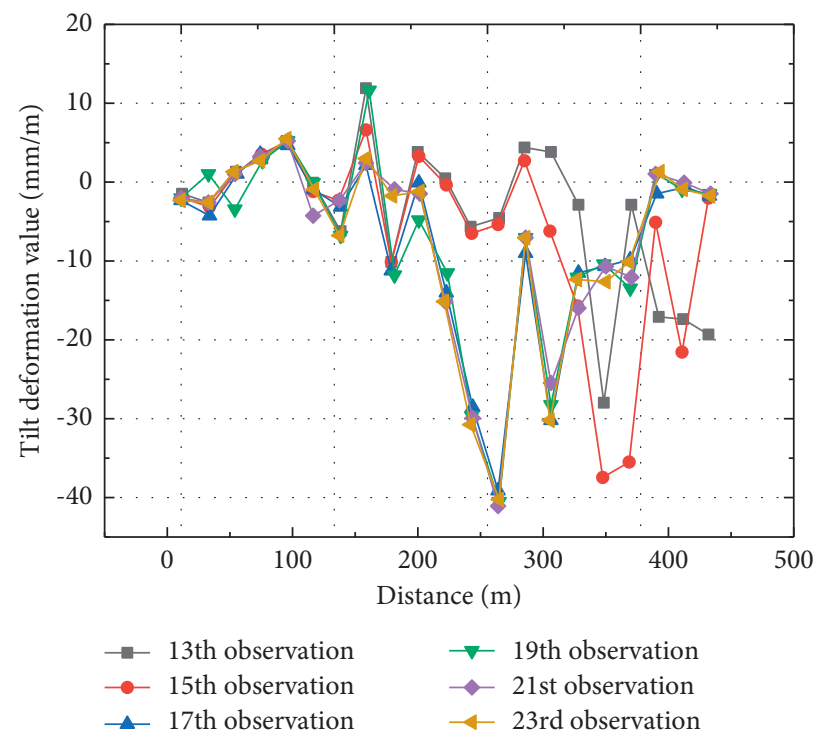

FIgURE 6: Inclined dynamic deformation curve of strike observation.

it can be seen that the whole slope moves downhill. Extrusion-induced surface uplift at the ravine is shown in Figure 13.

4.1.2. Range of Surface Movement in Hilly Areas. Due to the influence of mountain topography, the horizontal movement, the horizontal deformation, and the surface uplift, occurring when the movement boundary is close to the plain or ravine, expand the range of movements in the uphill and downhill directions, thus reducing the boundary angle and movement angle of movement deformation. As can be known from the comprehensive histogram of the coal seam in the mine, the overlying stratum belongs to medium-hard rock. According to Table 1 in the literature [1] and the actual condition (dip angle $5.0^{\circ}$ ) of $\mathrm{P} 2$ working face, the boundary angle on strike, dip boundary angle, rise boundary angle, movement angle on strike, dip movement angle, and rise movement angle of P2 working face can be acquired (Tables 1 and 2). Compared with those of the plain, the measured boundary angle and movement angle of P2 working face are reduced to varying degrees. Specifically, compared with the theoretical values, the boundary angle on strike is reduced by $5^{\circ}-10^{\circ}$, and the rise boundary angle is reduced by $2^{\circ}-7^{\circ}$; the movement angle on strike is reduced by $8^{\circ}-13^{\circ}$, the rise movement angle is reduced by $0^{\circ}-10^{\circ}$, and the dip movement angle is reduced by $2^{\circ}-16^{\circ}$, as listed in Tables 1 and 2 . 


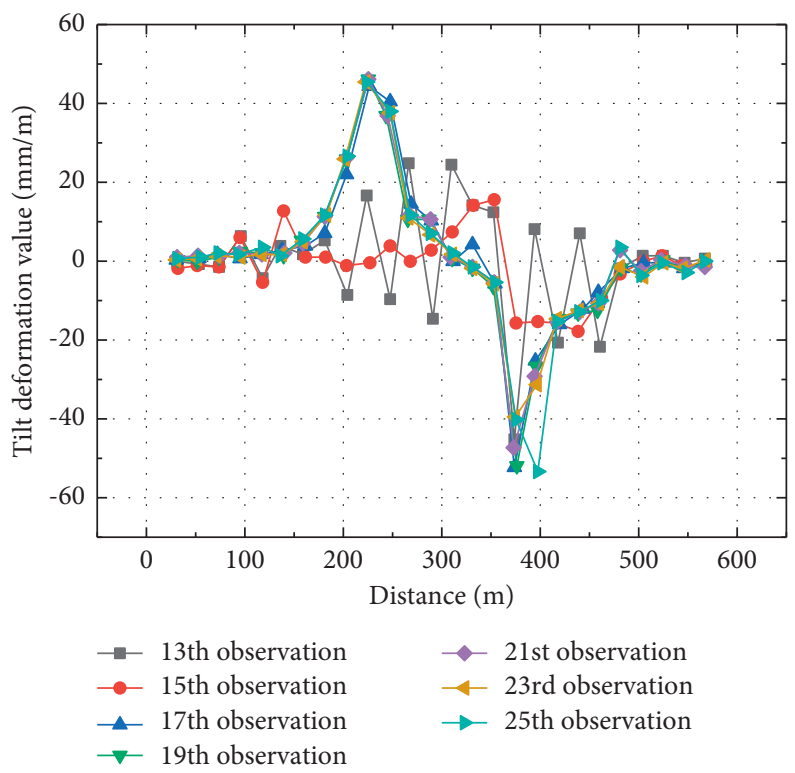

Figure 7: Dynamic deformation curve of inclination observation line B.

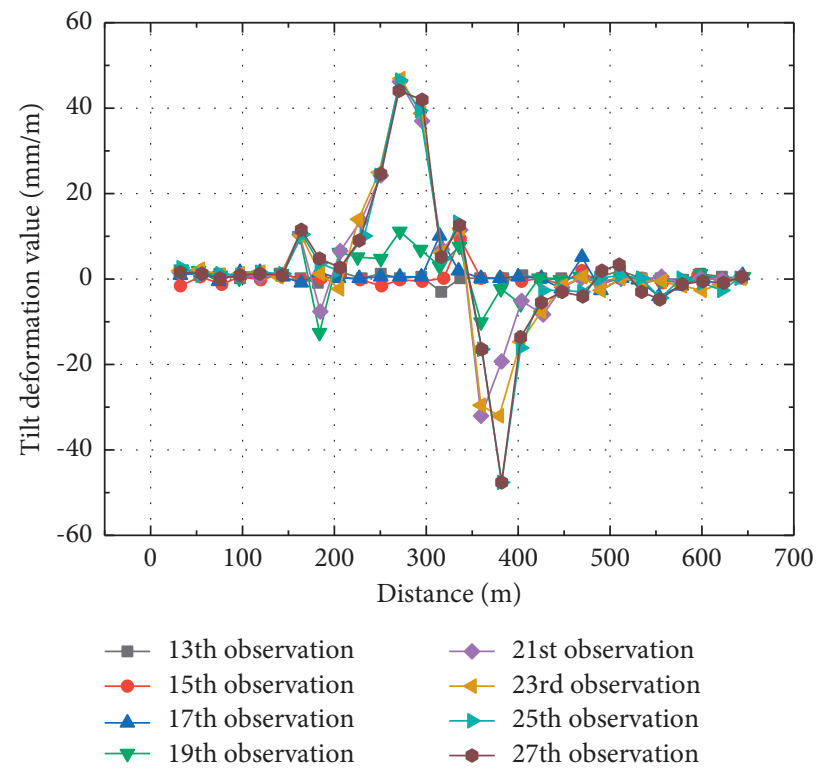

FIgURE 8: Dynamic deformation curve of inclination observation line C.

4.2. Analysis of Mining Sufficiency. In the final subsidence curves of lines B and C on inclination on P2 working face, no flat bottom occurs in the moving basin, and the maximum subsidence value appears only at one point in its central part. The maximum subsidence value $(3167 \mathrm{~mm})$ of line B appears at point B15, while that $(3419 \mathrm{~mm})$ of line $\mathrm{C}$ appears at point $\mathrm{C} 16$. The maximum subsidence value of line $\mathrm{C}$ is greater than the average subsidence value $(3362 \mathrm{~mm})$ in the flat bottom in the moving basin of line A. It can be inferred that only one observation point (point $\mathrm{C} 16$ ) of line $\mathrm{C}$ has reached the maximum subsidence value under the geological mining conditions, so critical full mining has been achieved on line C. In view of the similar buried depths of lines B and C, it can be summarized that only one observation point of lines $\mathrm{B}$ and $\mathrm{C}$ on inclination has reached the maximum subsidence value under the mining geological conditions, so critical full mining has been achieved on the two lines.

In light of the literature [28], the surface is fully mined when the length or width of the gob area reaches or exceeds $H_{0}$, namely, the average mining depth (ratio 1.2-1.4). P2 working face is $1138 \mathrm{~m}$ long and $220 \mathrm{~m}$ wide, and the average depths of lines A, B, and C are $208 \mathrm{~m}, 200 \mathrm{~m}$, and $206 \mathrm{~m}$, respectively. That is, the ratios of mining length to mining height at line A in P2 working face is 5.47, and the ratios of mining width to mining height at lines $\mathrm{B}$ and $\mathrm{C}$ in $\mathrm{P} 2$ working face are 1.1 and 1.07, respectively. In other words, 


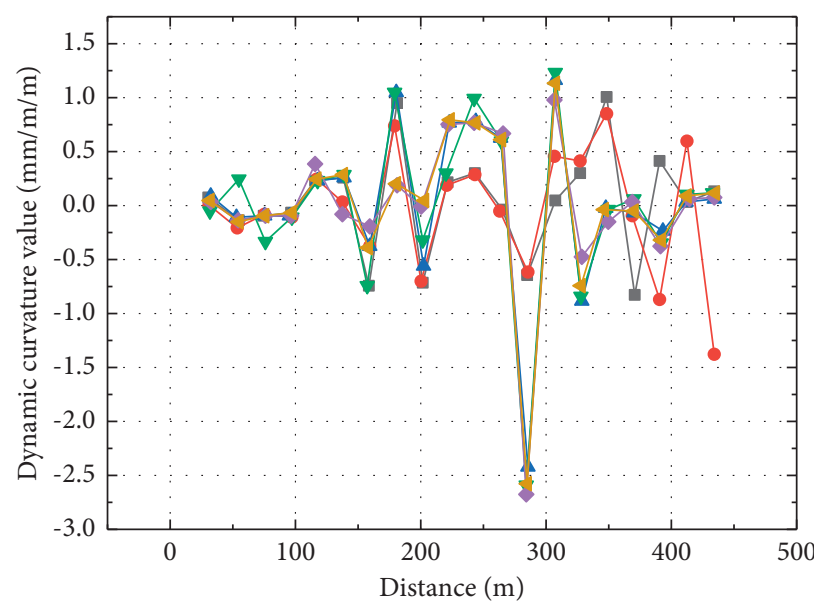

$$
\begin{array}{ll}
\rightarrow \text { 13th observation } & - \text { 19th observation } \\
\rightarrow-\text { 15th observation } & - \text { 21st observation } \\
- \text { 17th observation } & - \text { 23rd observation }
\end{array}
$$

Figure 9: Curvature dynamic deformation curve of strike observation line A.

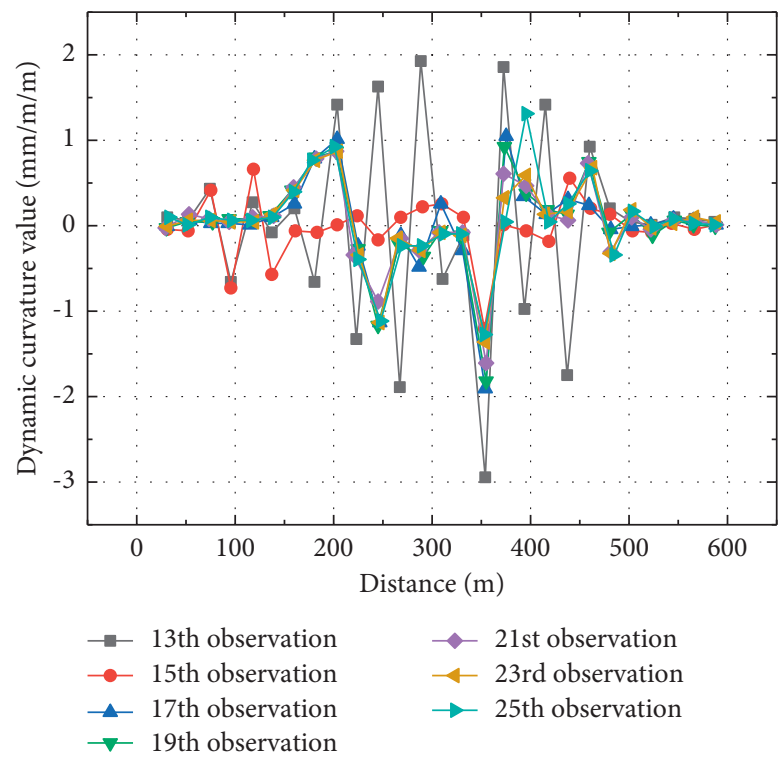

Figure 10: Dynamic deformation curve of B-line curvature of tendency observation.

P2 working face with thick bedrock can achieve full mining more easily than those of general geological conditions. It can achieve critical full mining at the ratio of mining width to mining depth of 1.07 .

4.3. Development and Morphology of Fractures. According to the field fracture investigation in the whole mining process of P2 working face, many large crisscross fractures appear on the surface, and these fractures exhibit obvious regularity in the strike direction. On the whole, they can be divided into two types. The first type is network fractures generated in bedrock-exposing areas (mainly occurring in the vicinity of A1-A6, A17-A19, and A28-A32 of line A, the whole line B, and $\mathrm{C} 7-\mathrm{C} 17$ of line $\mathrm{C}$ ), and the other type is large fractures in loess-covering areas (mainly occurring near A7-A11 of line $\mathrm{A}$ and $\mathrm{C} 1-\mathrm{C} 6$ and $\mathrm{C} 8-\mathrm{C} 36$ of line $\mathrm{C}$ ).

As shown in Figure 14, the widths of bedrock surface fractures mostly lie in the range of $20-200 \mathrm{~mm}$, with the maximum width being up to $300 \mathrm{~mm}$. Depths of the fractures differ, with the maximum measured depth being about 10-20 m. Generally, the directions of the fractures are related to the mountain topography; most of the fractures are perpendicular to the downhill direction of the slope and develop approximately along the contour, forming a crisscross fracture network.

As shown in Figure 15, widths of fractures on the loesscovering surface are relatively large, with the maximum width reaching $0.5 \mathrm{~m}$. Besides, these fractures possess a fall of about $0.2 \mathrm{~m}$ generally and over $1 \mathrm{~m}$ partially. At the edge of 


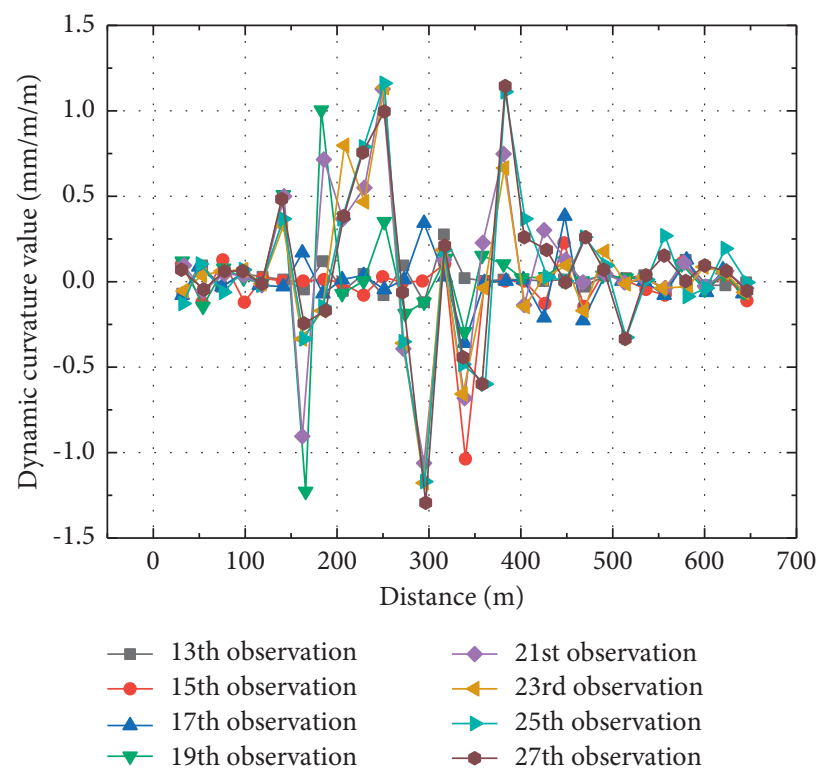

FIgURE 11: Dynamic deformation curve of c-line curvature in tendency observation.
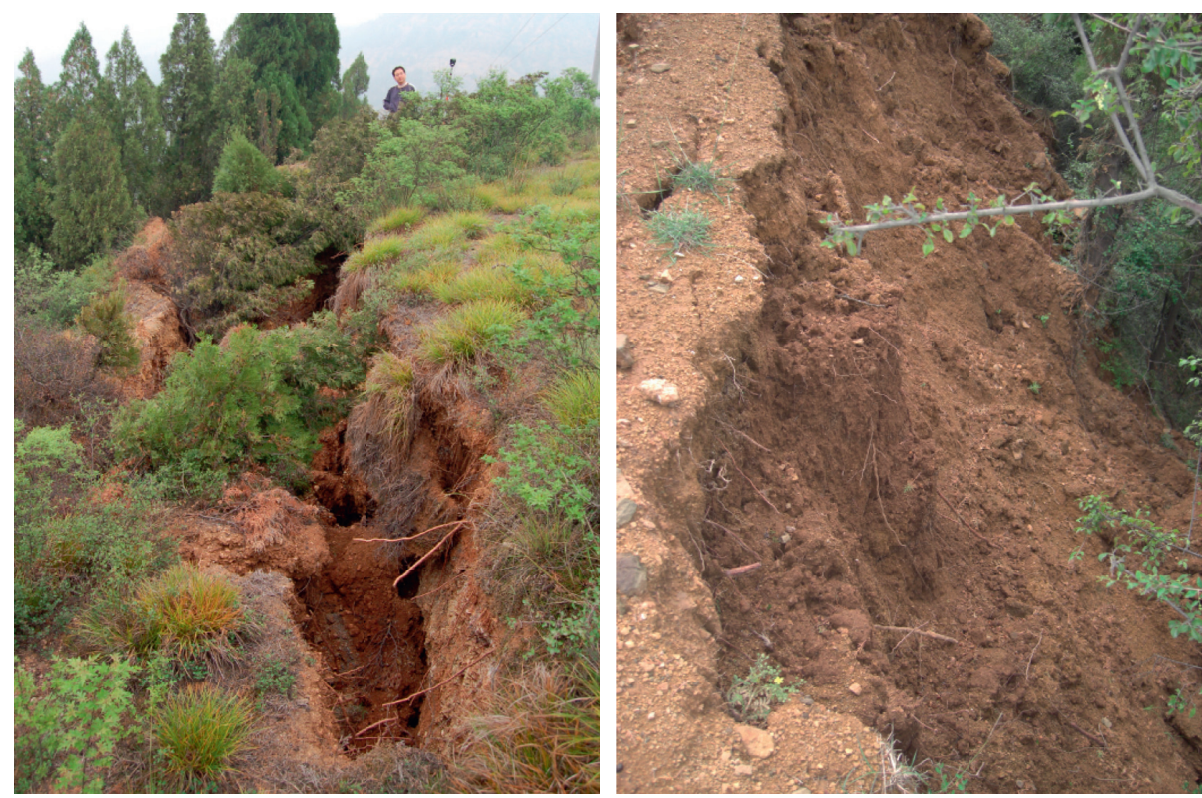

Figure 12: Point 1: soil collapse and landslide at the edge of gully.

the slope, there also occurs an overall slump towards the downhill direction. For example, an overall slump occurs at point A11 of line A, where the root system of vegetation is exposed (Figure 12). Loess-covering surface fractures at nonslope positions often collapse to fill in the fractures (Figure 15).

\section{Surface Movement Duration and Subsidence Speed}

5.1. Duration of Surface Movement. As shown in Figure 3, subsidence at point A25 in line A begins at the eighth observation and stabilizes at the tenth observation. The observation at point A25 lasts $77 \mathrm{~d}$. Point A23, one of the maximum subsidence points in line $A$, starts to subside at the eighth observation. According to the observation records, the working face advances to a position $860.3 \mathrm{~m}$ away from the open-off cut during the seventh observation and to a position $971.7 \mathrm{~m}$ away from the open-off cut during the eighth observation. That is, the working face advances for $111.4 \mathrm{~m}$ within $46 \mathrm{~d}$, and the advancement speed is $2.42 \mathrm{~m} / \mathrm{d}$ during the observation. It can be inversely calculated that point A23 (about $63 \mathrm{~m}$ away from point A25) started to subside $26 \mathrm{~d}$ ago, which means the total surface stabilization time at point A23 is $77+26=103 \mathrm{~d}$. As shown in Figure 4, point B15 is the observation point with the maximum 

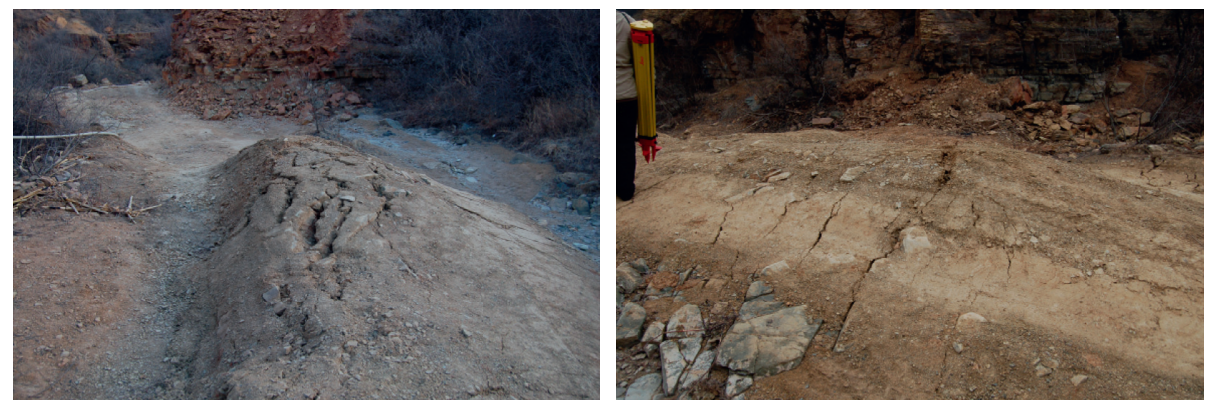

FIgURE 13: Point 2: fractures and uplift at the ravine.

TABLE 1: Boundary angles of observation lines on strike and inclination.

\begin{tabular}{|c|c|c|c|c|c|c|}
\hline \multirow[b]{2}{*}{ Observation line } & \multicolumn{2}{|c|}{ Boundary angle on strike $\delta_{0}$} & \multicolumn{2}{|c|}{ Rise boundary angle $\gamma_{0}$} & \multicolumn{2}{|c|}{ Dip boundary angle $\beta_{0}$} \\
\hline & Measured value & Theoretical value & Measured value & Theoretical value & Measured value & $\begin{array}{c}\text { Theoretical } \\
\text { value }\end{array}$ \\
\hline Obser & $50^{\circ}$ & $55^{\circ}-60^{\circ}$ & - & - & - & - \\
\hline Observation line B on inclination & - & - & $60^{\circ}$ & & $50^{\circ}$ & \\
\hline Observation line $\mathrm{C}$ on inclination & - & - & $58^{\circ}$ & $55-60$ & $50^{\circ}$ & $52-57$ \\
\hline
\end{tabular}

TABLe 2: Movement angles of observation lines on strike and inclination.

\begin{tabular}{|c|c|c|c|c|c|c|}
\hline \multirow[b]{2}{*}{ Measuring line } & \multicolumn{2}{|c|}{ Movement angle on strike $\delta$} & \multicolumn{2}{|c|}{ Rise movement angle $\gamma$} & \multicolumn{2}{|c|}{ Dip movement angle $\beta$} \\
\hline & Measured value & Theoretical value & Measured value & Theoretical value & Measured value & $\begin{array}{c}\text { Theoretical } \\
\text { value }\end{array}$ \\
\hline Observation line $\mathrm{A}$ on strike & $62^{\circ}$ & $70^{\circ}-75^{\circ}$ & - & - & - & \\
\hline Observation line B on inclination & - & - & $70^{\circ}$ & $70^{\circ}-75^{\circ}$ & $65^{\circ}$ & $67^{\circ}-72^{\circ}$ \\
\hline Observation line $\mathrm{C}$ on inclination & - & - & $65^{\circ}$ & $70-75$ & $56^{\circ}$ & $67-72$ \\
\hline
\end{tabular}

subsidence value in line $B$. It does not subside at the sixth observation, reaches the maximum value at the ninth observation, and tends to stabilize later. The stage lasts $133 \mathrm{~d}$. Hence, maximum surface stabilization time is deduced to be 133 d. As shown in Figure 5, point C16 in line C does not begin to subside at the second observation and basically stabilizes at the sixth observation. The stage lasts $108 \mathrm{~d}$. Therefore, the maximum surface stabilization time is inferred to be $108 \mathrm{~d}$.

With reference to literature [66], the duration of surface movement can be determined based on the measured data in this mining area. When there is no measured data, the duration ( $T$ ) of surface movement can be calculated according to the following formula:

$$
T=2.5 H_{0}\left(H_{0} \leq 400 \mathrm{~m}\right) .
$$

It is worked out that $208 * 2.5=520 \mathrm{~d}, 200 * 2.5=500 \mathrm{~d}$, and $206 * 2.5=515 \mathrm{~d}$ are required for lines A, B, and C. As revealed by the previous analysis, the surface subsidence stabilization times of lines $\mathrm{A}$ and $\mathrm{C}$ are closer to the actual values than that of line $\mathrm{B}$. Their average subsidence stabilization time and theoretically calculated subsidence stabilization time are $(108+103) \div 2=105.5 \mathrm{~d}$ and $(520+515) \div$ $2=517.5 \mathrm{~d}$, respectively. Obviously, the actual subsidence stabilization time is much shorter than and only $105.5 \div 517.5=20 \%$ of the theoretically calculated value. This result manifests that the fully mechanized caving mining working face with thick bedrock can achieve surface stabilization more easily. In addition, the time required for subsidence stabilization of bedrock-exposing surface is short, with the required time ratio being $108 / 103=1.05$. The subsidence stabilization times of thick bedrock-exposing surface and thick bedrock surface with thin epipedon are basically the same.

5.2. Maximum Surface Subsidence Speed. Surface subsidence speed refers to the subsidence amount per unit time caused by underground mining. Each point (A1-A21) on the observation line on strike of the surface movement observation station has reached the maximum subsidence, so the calculation of the surface subsidence speed can be figured out by using multiperiod observation results at any point. The observation values and calculation results of each period are disclosed in Table 3.

As given in Table 3, the subsidence difference from the fifth observation to the sixth observation is $\Delta W=2363 \mathrm{~mm}$, and the observation interval is $t=20 \mathrm{~d}$. The maximum surface subsidence speed can be calculated according to the following formula:

$$
V_{\text {Max }}=\frac{\Delta W}{t}=\frac{2363}{20}=\frac{118.20 \mathrm{~mm}}{d} .
$$

In fact, except for the maximum subsidence speed $118.20 \mathrm{~mm} / \mathrm{d}$, the subsidence speeds at other times are 

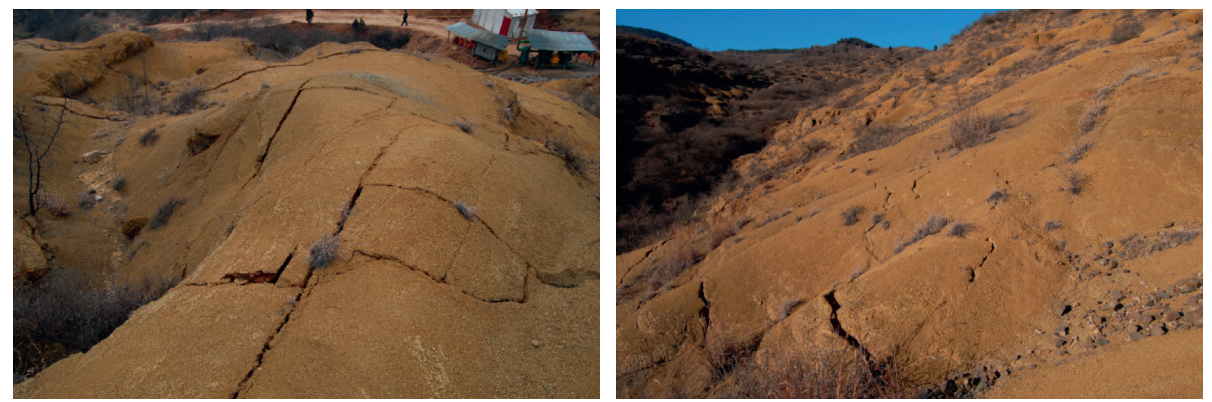

FIgURE 14: Point 3: surface rock fractures above the working face.
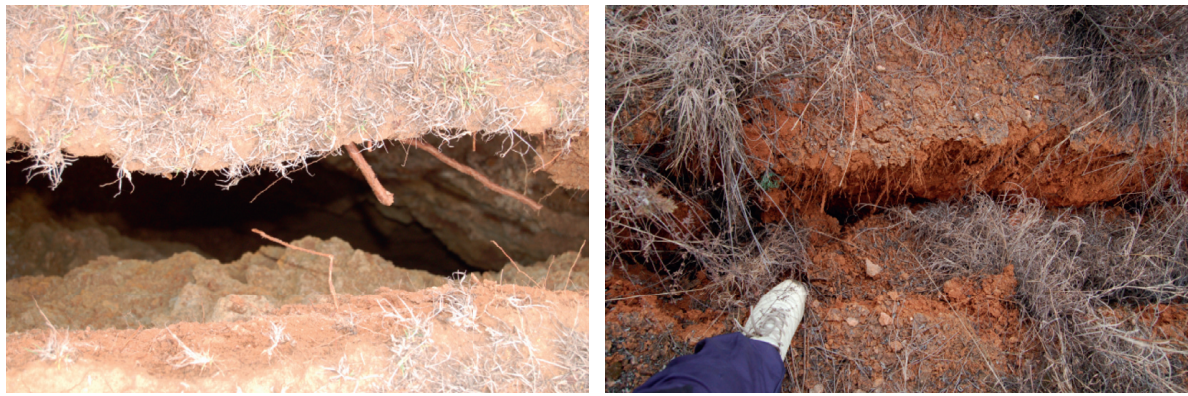

FIgURE 15: Point 4: surface soil fractures above the working face.

TABle 3: Calculation of subsidence speed of the maximum subsidence point.

\begin{tabular}{|c|c|c|c|c|c|c|c|}
\hline Serial number & Observa & tion date & $W(\mathrm{~mm})$ & $\begin{array}{c}\text { Days } \\
\text { interval }\end{array}$ & $\begin{array}{l}\text { Subsidence interval difference } \\
(\mathrm{mm})\end{array}$ & $\begin{array}{c}V \\
(\mathrm{~mm} / \text { day }) \\
\end{array}$ & $\begin{array}{l}\text { Distance to working } \\
\text { face }(\mathrm{m})\end{array}$ \\
\hline 1 & 1st observation & 2nd observation & 11 & 27 & 299 & 11.1 & -198.0 \\
\hline 2 & 3rd observation & 4th observation & 310 & 35 & 293 & 8.4 & -129.9 \\
\hline 3 & 5th observation & 6th observation & 603 & 23 & 367 & 16.0 & -67.7 \\
\hline 4 & 7th observation & 8th observation & 970 & 20 & 2363 & 118.2 & 35.8 \\
\hline 5 & 9th observation & 10th observation & 3333 & 37 & 40 & 1.1 & 153.3 \\
\hline 6 & 11th observation & 12th observation & 3373 & 48 & 45 & 0.9 & 333.3 \\
\hline 7 & 13th observation & 14th observation & 3418 & 46 & 1 & 0.02 & - \\
\hline
\end{tabular}

relatively low. This indicates that considerable surface subsidence occurs in a short period of time, and overburden subsidence is sudden and violent. Given the characteristics in hilly areas, when serious discontinuous damage appears on the surface, the possibility of sudden discontinuous movement and deformation such as large fractures, landslides, and collapses will increase (Figure 12).

\section{Conclusions}

(1) The upper part of the slope in hilly areas slides towards the downhill direction under the action of tensile stress or push stress. As a result, the ranges of horizontal movement and subsidence towards the downhill direction both increase. Affected by the sliding in the ravine of the mountain, the ground may be extruded and deformed, leading to the surface uplift at the ravine, an increase in the range of ground surface movement, and decreases in the movement angle and the boundary angle. In addition, the surface movement duration of HIFMCMWFSTBTE in hilly areas is relatively short. Considerable subsidence will occur in the active stage, and the surface subsidence is sudden and violent. The measured surface stabilization time of P2 working face is only $20 \%$ of the calculated value in the Specification.

(2) HIFMCMWFSTBTE can achieve full mining more easily than those of other geological conditions. Its critical value of full mining is smaller than the ratio (1.2-1.4) of mining width to mining depth in traditional experience. According to the field measurement, critical full mining can be achieved in P2 working face when the ratio of mining width to mining depth is 1.07.

(3) HIFMCMWFSTBTE is prone to serious sudden discontinuous and strongly regular damage. Fractures on the gully region surface develop along the contour, forming a crisscross fracture network. Fractures on the horizontal surface are approximately parallel to the working face. Fractures on the 
loess-covering surface open with the mining of the working face first and then close or decrease in width, and fractures on the bedrock-exposing surface are not easy to close after being generated.

\section{Data Availability}

Some or all data, models, or codes that support the findings of this study are available from the corresponding author upon reasonable request.

\section{Conflicts of Interest}

The authors declare that they have no conflicts of interest.

\section{Acknowledgments}

This work was financially supported by National Natural Science Foundation of China (52174108, 51974105, and 52104127) and sponsored by Program for Science\&Technology Innovation Talents in Universities of Henan Province (21HASTIT024), Open Fund of State Key Laboratory of Water Resource Protection and Utilization in Coal Mining (GJNY-1873.16), State Key Laboratory of Coal Resources in Western China (SKLCRKF1912 and SKLCRKF20-01), scientific and technological innovation research team of Henan Polytechnic University (T2021-5), China Postdoctoral Science Foundation (no. 2021M701100), Fundamental Research Funds for the Universities of Henan Province (NSFRF200332 and NSFRF210303), Key Research and Development and Promotion of Special (Science and Technology) Project of Henan Province (212102310379 and 202102310542), the research fund of Henan Key Laboratory for Green and Efficient Mining and Comprehensive Utilization of Mineral Resources (Henan Polytechnic University) (KCF201804 and KCF202002), the Key Scientific Research Projects of Colleges and Universities in Henan Province (21A610005, 20B440001, and 21A440003), and the Henan Science and Technology Research Project (21210230399). The authors greatly appreciate the support.

\section{References}

[1] M. He, W. Gong, J. Wang et al., "Development of a novel energy-absorbing bolt with extraordinarily large elongation and constant resistance," International Journal of Rock Mechanics and Mining Sciences, vol. 67, pp. 29-42, 2014.

[2] M. C. He, H. P. Xie, S. P. Peng, and Y. D. Jiang, "Study on rock mechanics in deep mining engineering," Chinese Journal of Rock Mechanics and Engineering, vol. 24, no. 16, pp. 28032813, 2005.

[3] J. Liu, Z. Chen, D. Elsworth, X. Miao, and X. Mao, "Evaluation of stress-controlled coal swelling processes," International Journal of Coal Geology, vol. 83, no. 4, pp. 446-455, 2010.

[4] J. Zhang, Q. Zhang, Q. Sun, R. Gao, D. Germain, and S. Abro, "Surface subsidence control theory and application to backfill coal mining technology," Environmental Earth Sciences, vol. 74, no. 2, pp. 1439-1448, 2015.

[5] A. Asadi, K. Shakhriar, and K. Goshtasbi, "Profiling function for surface subsidence prediction in mining inclined coal seams," Journal of Mining Science, vol. 40, no. 2, pp. 142-146, 2004.
[6] Z. Song, Y. Wang, H. Konietzky, and X. Cai, "Mechanical behavior of marble exposed to freeze-thaw-fatigue loading," International Journal of Rock Mechanics and Mining Sciences, vol. 138, Article ID 104648, 2021.

[7] Z. Song, H. Konietzky, and M. Herbst, "Bonded-particle model-based simulation of artificial rock subjected to cyclic loading," Acta Geotechnical, vol. 14, 2019.

[8] Z. Song, T. Frühwirt, and H. Konietzky, "Inhomogeneous mechanical behaviour of concrete subjected to monotonic and cyclic loading," International Journal of Fatigue, vol. 132, Article ID 105383, 2020.

[9] X. Zhu, G. Guo, H. Liu, and X. Yang, "Surface subsidence prediction method of backfill-strip mining in coal mining," Bulletin of Engineering Geology and the Environment, vol. 78, no. 8, pp. 6235-6248, 2019.

[10] W. Quanyuan, P. Jiewu, Q. Shanzhong et al., "Impacts of coal mining subsidence on the surface landscape in Longkou city, Shandong Province of China," Environmental Earth Sciences, vol. 59, no. 4, pp. 783-791, 2009.

[11] S. Chen, D. Yin, F. Cao, Y. Liu, and K. Ren, "An overview of integrated surface subsidence-reducing technology in mining areas of China," Natural Hazards, vol. 81, no. 2, pp. 1129-1145, 2016.

[12] S. Gong, "Investigation of tensile and fracture mechanical properties of bituminous coal at different strain rates," Journal of Materials Research and Technology, vol. 15, pp. 834-845, 2021.

[13] C. Liu, H. Li, and H. Mitri, "Effect of strata conditions on shield pressure and surface subsidence at a longwall top coal caving working face," Rock Mechanics and Rock Engineering, vol. 52, no. 5, pp. 1523-1537, 2019.

[14] D. Xuan, J. Xu, B. Wang, and H. Teng, "Borehole investigation of the effectiveness of grout injection technology on coal mine subsidence control," Rock Mechanics and Rock Engineering, vol. 48, no. 6, pp. 2435-2445, 2015.

[15] A. M. Suchowerska Iwanec, J. P. Carter, and J. P. Hambleton, "Geomechanics of subsidence above single and multi-seam coal mining," Journal of Rock Mechanics and Geotechnical Engineering, vol. 8, no. 3, pp. 304-313, 2016.

[16] S. Dong, H. Yin, S. Yao, and F. Zhang, "Detecting surface subsidence in coal mining area based on DInSAR technique," Journal of Earth Sciences, vol. 24, no. 3, pp. 449-456, 2013.

[17] W. Sun, Q. Zhang, Y. Luan, and Z. Xiao-Ping, "A study of surface subsidence and coal pillar safety for strip mining in a deep mine," Environmental Earth Sciences, vol. 77, no. 17, pp. 1-16, 2018.

[18] C. Gao, Y. J. Zhang, P. Li, N. Xu, and G. Tian, "Experimental study on law of surface subsidence under the condition of large mining depth and thick bedrock," Safety In Coal Mines, vol. 52, no. 5, pp. 201-206, 2021.

[19] S. Peng and Y. Bi, "Strategic consideration and core technology about environmental ecological restoration in coal mine areas in the Yellow River basin of China," Journal of China Coal Society, vol. 45, no. 4, pp. 1211-1221, 2020.

[20] S. J. Song, X. G. Zhao, S. M. Wang, and Y. Zhang, "Analysis of the influence of overburden rock soil ratio on mining subsidence in Yushen mining area," Safety in Coal Mines, vol. 47, no. 5, pp. 200-204, 2016.

[21] E. Fathi Salmi, M. Nazem, and M. Karakus, "Numerical analysis of a large landslide induced by coal mining subsidence," Engineering Geology, vol. 217, pp. 141-152, 2017.

[22] Y. Sun, J. Zuo, M. Karakus, and L. Lei, "A new theoretical method to predict strata movement and surface subsidence 
due to inclined coal seam mining," Rock Mechanics and Rock Engineering, vol. 54, no. (4), pp. 1-18, 2021.

[23] P. Sopata, T. Stoch, A. Wójcik, and D. Mrocheń, "Land surface subsidence due to mining-induced tremors in the upper silesian coal basin (Poland)-Case study," Remote Sensing, vol. 12, no. 23, 2020.

[24] C. Zhang, F. Wang, and Q. Bai, "Underground space utilization of coalmines in China: a review of underground water reservoir construction," Tunnelling and Underground Space Technology, vol. 107, Article ID 103657, 2021.

[25] Y. Wang, B. Zhang, S. H. Gao, and C. H. Li, "Investigation on the effect of freeze-thaw on fracture mode classification in marble subjected to multi-level cyclic loads," Theoretical and Applied Fracture Mechanics, vol. 111, Article ID 102847, 2021.

[26] J. Tang, J. Qiao, Z. Liu, X. Zhou, G. Yu, and J. Zhao, "Mechanism characteristic analysis and soft measuring method review for ball mill load based on mechanical vibration and acoustic signals in the grinding process," Minerals Engineering, vol. 128, pp. 294-311, 2018.

[27] X. Zhu, X. Chen, N. Zhang, X. Wang, and H. Diao, "Experimental and numerical research on triaxial mechanical behavior of self-compacting concrete subjected to freeze-thaw damage," Construction and Building Materials, vol. 288, Article ID 123110, 2021.

[28] W. B. Guo, G. B. Zhao, and E. H. Bai, "Critical failure of overlying rock strata and its criteria induced by high-intensity longwall mining," Journal of China Coal Society, vol. 45, no. 11, pp. 3657-3666, 2020. 